\title{
IPTEK BAGI MASYARAKAT SISTEM INFORMASI MANAJEMEN ADMINISTRASI DESA BERBASIS WEB DI DESA SEKARAN KECAMATAN SIMAN - PONOROGO
}

\author{
Aziz Musthafa ${ }^{1}$, Shoffin Nahwa Utama ${ }^{2}$ \\ ${ }^{1,2}$ Fakultas Sains dan Teknologi, Universitas Darussalam Gontor \\ Email: aziz@unida.gontor.ac.id
}

\begin{abstract}
The development of technology is very influential on community service in the village. Therefore, Sekaran Village Siman District Ponorogo District has made various improvements, including one of the information systems. With a location that is not too far from the University of Darussalam Gontor makes basis why people empowerment in Sekaran village as a partner is held. The condition of administration service system in the Village is still conventional or manual. Such as (a) data storage of villagers is still in the register books; (b) data storage archives, especially letters from villages have not implemented application based information systems. This has become influential to the villagers or village officials, where human errors often occur, the service queue, and a waste of time and cost. Therefore we need a system to overcome the existing problems. Based on the problem, implementer people empowerment develop Sistem Administrasi Desa (SIMADES) to facilitate the service of residents data and administration.
\end{abstract}

Keywords: Information System, SIMADES, administration

\begin{abstract}
Abstrak. Perkembangan teknologi yang cepat sangat berpengaruh terhadap pelayanan masyarakat dilingkup desa. Oleh karena itu Desa Sekaran Kecamatan Siman Kabupaten Ponorogo telah melakukan berbagai peningkatan, termasuk salah satunya peningkatan sistem informasi. Dengan lokasi yang tidak terlalu jauh dari Universitas Darussalam Gontor menjadikan dasar mengapa pengabdian masyarakat di Desa Sekaran sebagai mitra diadakan. Kondisi sistem pelayanan administrasi kependudukan di Desa saat ini masih bersifat konvensional atau manual, seperti: (a) Pencatatan data penduduk desa dalam buku - buku register; (b) Pendataan arsip khususnya suratmenyurat belum menerapkan sistem informasi berbasis aplikasi. Hal tersebut berimbas kepada perangkat desa maupun penduduk desa, dimana sering terjadi human error, antrian pelayanan, serta pemborosan waktu dan biaya. Oleh karena itu dibutuhkan suatu sistem untuk mengatasi permasalahan yang ada. Berdasarkan masalah tersebut, pelaksana pengabdian masyarakat melakukan pengembangan Sistem Informasi Desa (SIMADES) untuk memudahkan pelayan data kependudukan dan administrasi. Kata kunci: Sistem Informasi, SIMADES, administrasi
\end{abstract}

\section{PENDAHULUAN}

Desa sebagai bagian terkecil dari sistem pemerintahan administratif di Indonesia, dituntut untuk dapat mengikuti perkembangan teknologi dan terus meningkatkan kemampuannya di dalam mengelola data administrasi kependudukan desa.

Desa Sekaran Kecamatan Siman Kabupaten Ponorogo. Dengan lokasi yang tidak terlalu jauh dari Kampus Universitas Darussalam Gontor menjadikan dasar pengabdian masyarakat di Desa Sekaran dilakukan. Dalam sistem pelayanan administrasi kependudukan di Desa saat ini masih bersifat konvensional atau manual, seperti: (a) Pencatatan data penduduk desa dalam buku - buku register; (b) Pendataan arsip khususnya surat-menyurat belum menerapkan sistem informasi berbasis aplikasi. Hal tersebut berimbas kepada perangkat desa maupun penduduk desa, dimana sering terjadi human error, antrian pelayanan, serta pemborosan waktu dan biaya. Oleh karena itu dibutuhkan suatu sistem untuk mengatasi permasalahan yang ada.

SIMADES hadir sebagai suatu paradigma yang memungkinkan seorang pegawai di perangkat desa bisa mengatur administrasi desa yang sudah terkomputersisasi. Salah satu fitur yang ada SIMADES adalah layanan pengolahan data administrasi kependudukan desa berupa web 
aplikasi.

Berdasarkan latar belakang yang telah dipaparkan, diharapkan dengan penggunaan SIMADES, perangkat desa dapat mudah akses kependudukan dan surat menyurat. Menjaga data lebih aman serta mengoptimalkan pemberdayaan waktu, dan menekan biaya operasional desa.

\section{Tujuan Pengabdian}

Tujuan dari pengabdian ini adalah:

1. Penambahan wawasan tentang sistem informasi administrasi pada lingkup desa.

2. Untuk memberikan kemudahan bagi perangkat desa dalam pengolahan data pendudukan dan surat-menyurat yang dibutuhkan.

3. Untuk mempercepat proses pelayanan administrasi kepada masyarakat.

\section{Target}

Target melalui aplikasi SIMADES ini yaitu :

1. Perangkat dapat mudah mengakses data kependudukan dan surat menyurat yang dibutuhkan.
2. Perangkat desa dapat mengarsip surat dan mencetaknya untuk pelayanan sehari hari di lingkungan desa.

3. Pelatihan SIMADES untuk perangkat desa diperlukan untuk memaksimalkan penguasaan terhadap sistem informasi yang diberikan kepada Desa Sekaran.

\section{Luaran}

Luaran pengabdian masyarakat ini berupa aplikasi SIMADES berbasis web, database arsip kependudukan, dan suratmenyurat dalam file PDF, Excel dan cetak.

\section{METODE PELAKSANAAN}

Metode yang digunakan saat pengabdian meliputi pembuatan aplikasi SIMADES dan pelatihan aplikasi. Metode pembuatan aplikasi mengadopsi Siklus Hidup Perangkat Lunak, atau waterfall yaitu dengan melalui lima tahap yang berkesinambungan membentuk suatu siklus daur hidup perancangan perangkat lunak Lebih jelasnya dapat digambarkan dalam tabel 1. berikut :

Tabel 1. Permasalahan dan solusi pada mitra

\begin{tabular}{llll}
\hline No & \multicolumn{1}{c}{ Permasalahan Mitra } & \multicolumn{1}{c}{ Solusi } & \multicolumn{1}{c}{ Metode } \\
\hline 1 & $\begin{array}{c}\text { Rendahnya sumber daya } \\
\text { teknologi pengelolaan data } \\
\text { administrasi desa khususnya } \\
\text { kependudukan dan surat } \\
\text { menyurat }\end{array}$ & $\begin{array}{l}\text { Membuat aplikasi } \\
\text { Sistem Informasi Desa }\end{array}$ & $\begin{array}{l}\text { Siklus Hidup } \\
\text { Perangkat Lunak }\end{array}$ \\
\hline 2 & $\begin{array}{l}\text { Rendahnya pengetahuan } \\
\text { teknologi terkait SIMADES }\end{array}$ & Pelatihan infrastruktur & Presentasi, \\
& & dan penggunaan & Praktek langsung, \\
& & SIMADES & Diskusi \\
\hline
\end{tabular}

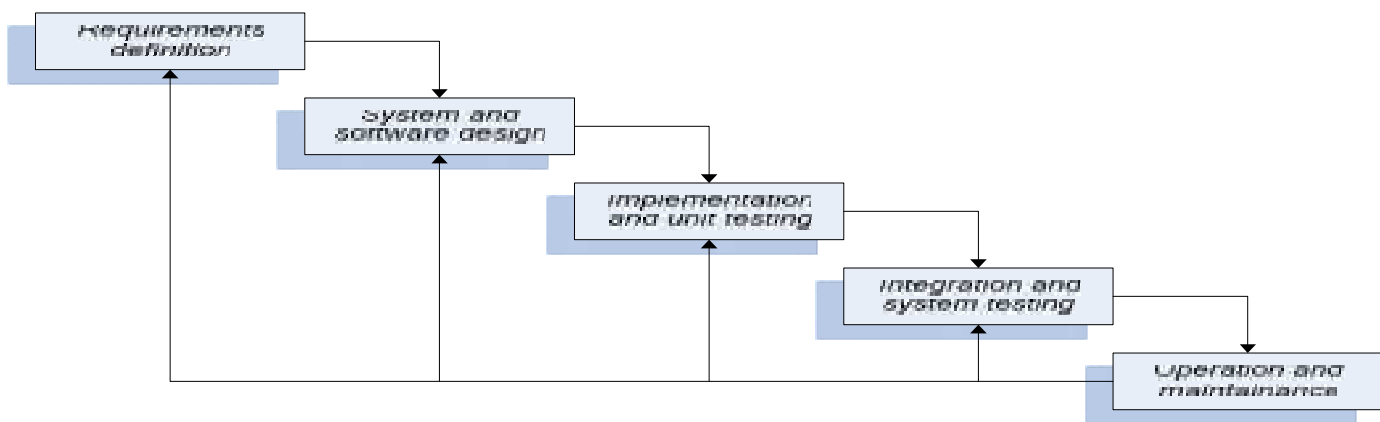

Gambar 1. Siklus Hidup Perangkat Lunak (Sommerville, 2011)

\section{Materi Pelatihan}

Materi pelatihan disampaikan dengan memberikan wawasan tentang sistem informasi administrasi pada lingkup desa dan pembahasan cara penggunaan aplikasi SIMADES. 


\section{Metode Penyampaian Pelatihan}

Untuk melaksanakan kegiatan tersebut digunakan metode ceramah untuk menjelaskan tentang kegunaan sistem informasi dalam administrasi dan tahapan penggunaan SIMADES.

\section{Khalayak Sasaran}

Sasaran kagiatan ini adalah Kepala Desa Sekaran beserta perangkatnya yang merupakan pengguna langsung dari aplikasi SIMADES berbasis web.

Waktu dan Tempat Pengabdian

Pengabdian ini dilaksanakan di Balai Desa yang terletak di Desa Sekaran, Kecamatan Siman, Kabupaten Ponorogo. Waktu pelaksanaan dari bulan Januari - Agustus 2017.

\section{Teknik Pengumpulan Data}

Tahap Studi Literatur yaitu suatu tahapan pengumpulan data dengan cara sebagai berikut :

1. Studi Wawancara

Tahap ini komunikasi langsung dengan

Kepala desa dan perangkat desa agar mengetahui tentang permasalahan yang ada di Manajemen Desa Sekaran.

2. Studi Dokumentasi

Dengan mengumpulkan informasi mengenai dokumen dan data-data yang diperlukan agar lebih mudah untuk didefinisikan. Hasil pengumpulan dokumen ada 11 jenis surat yaitu : Surat kelahiran, Surat SKCK, Surat Pindah, Surat Bepergian, Surat Status Nikah, Surat Ijin Keramaian, Surat Mendirikan Bangunan, Surat Pernah Sekolah, Surat Keterangan Miskin, Surat Dispen Nikah, dan Surat Keterangan. Selain itu terdapat buku induk kependudukan.

\section{Evaluasi}

Evaluasi dilakukan selama proses akhir pengabdian seusai aplikasi diujikan. Yang dilakukan adalah membagikan angket kepuasan pelaksanaan pengabdian dan penggunaan aplikasi. Dari hasil angket dapat mengidentifikasi tingkat kepuasan dalam pelaksanaan pengabdian dan tingkat pencapaian tujuan pengabdian kepada masyarakat.

\section{HASIL DAN PEMBAHASAN}

Pelaksanaan pengabdian masyarakat terdapat 2 tahapan yaitu :

\section{Tahap 1 : Implementasi SIMADES}

Awal pengabdian dibuka oleh Kepala Desa Bapak Minim Subarno beserta jajaran perangkat desa. Dalam sambutannya beliau mengapresiasi acara pengabdian masyarakat ini dan dimohon untuk segera melaksanakan agar baik infrastruktur maupun aplikasi dapat digunakan oleh perangkat desa

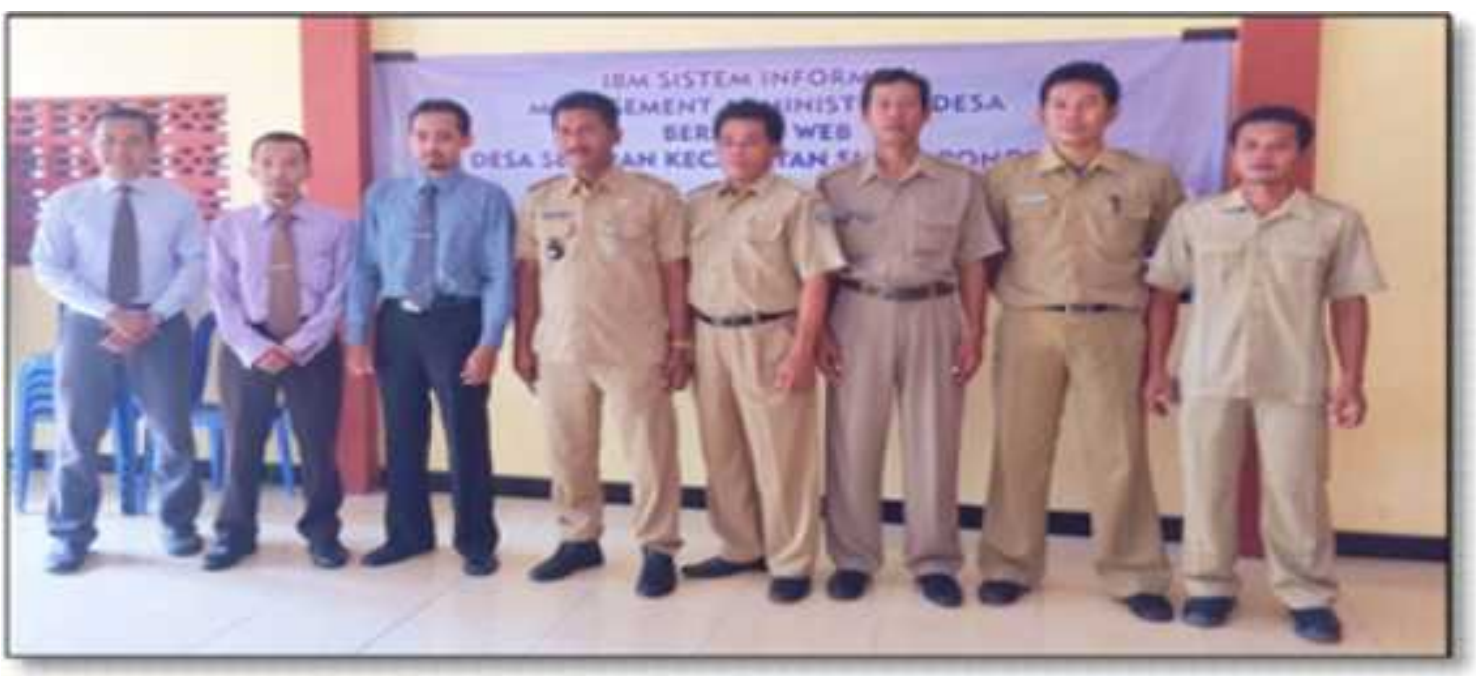

Gambar 2. Pembukaan Pengabdian Masyarakat 


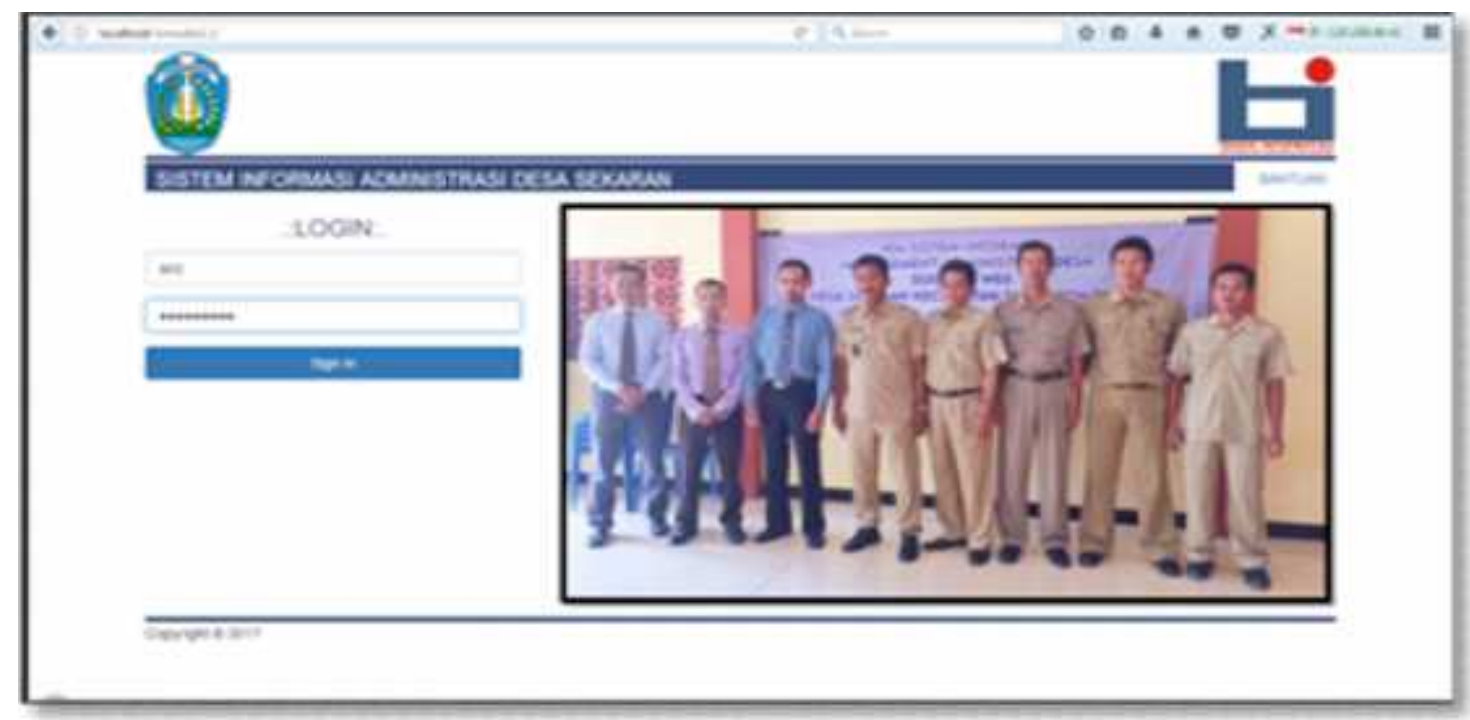

Gambar 3. Halaman Login SIMADES

Pada form login terdapat pengecekan user baik admin web atau admin desa (perangkat). menginstall aplikasi dan hanya memerlukan Karena berbeda level user akan ada perbedaan web browser diperangkat tersebut. juga pada akses menu web pada halaman utama. Selain itu, terdapat fitur responsive yang berguna untuk mengakses dari media smartphone atau tablet. Sehingga konten web akan beradaptasi dengan layar media. Dengan Framework bootstrap, web dapat diakses Pada form utama terdapat komponen berupa menu pilihan untuk menjalankan aplikasi dan informasi tambahan yang membantu perangkat desa dalam mendapatkan info cepat terkait data kependudukan. Info tersebut seperti jumlah usia kerja, jumlah surat keluar jumlah diperangkat smartphone ataupun tablet tanpa

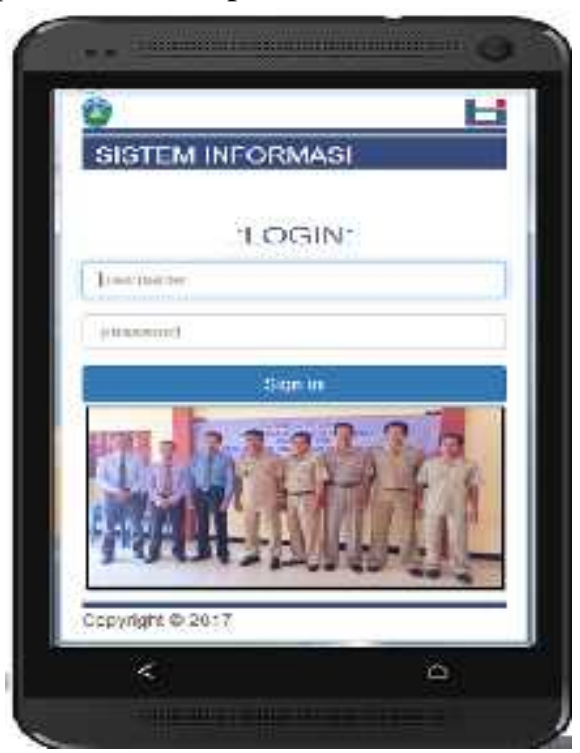

Gambar 4. Halaman Login SIMADES dengan layout interface versi mobile 
Musthafa, Utama, Iptek Bagi Masyarakat Sistem Informasi... 5

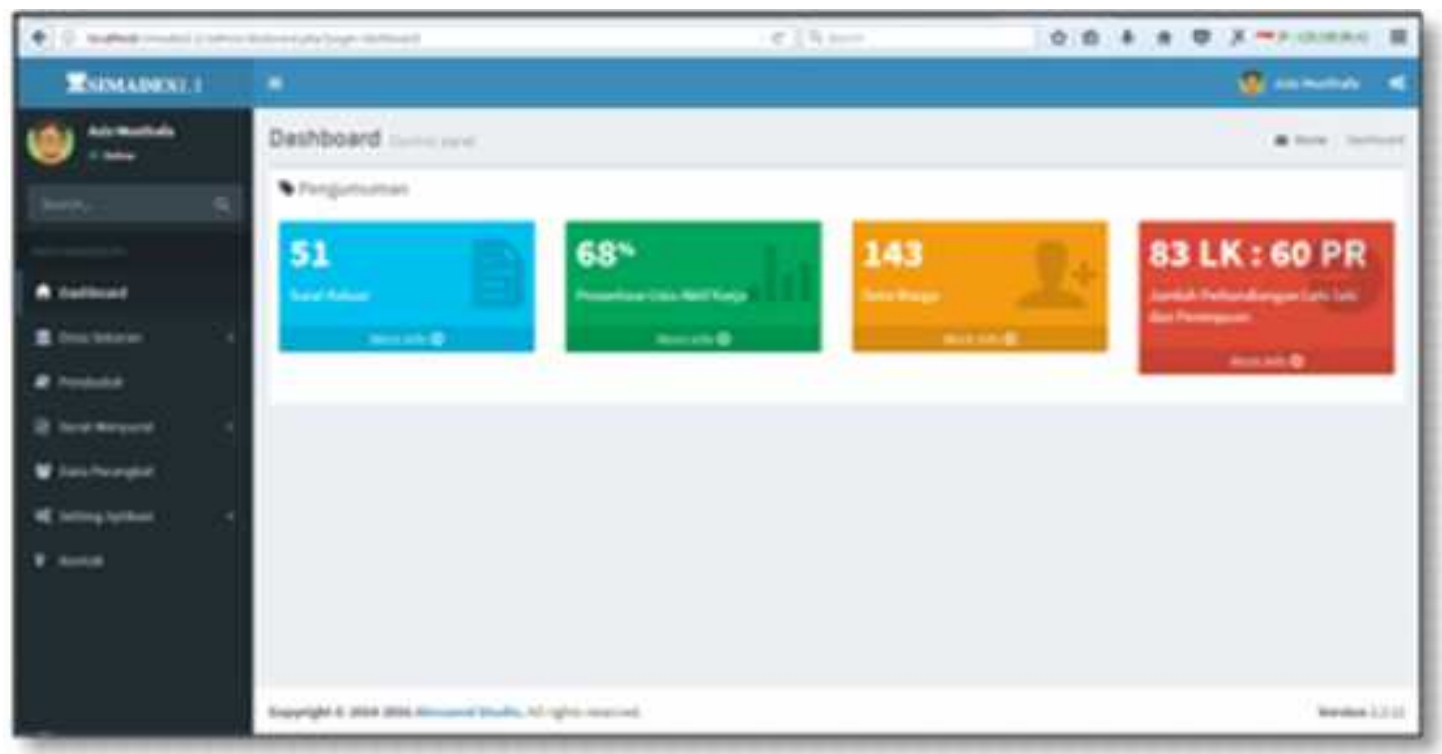

\section{Gambar 5. Halaman administrasi SIMADES}

Pada form pendataan penduduk terdapat menyurat Pada Form surat-menyurat tersedia fasilitas tambah warga, edit, hapus dan lihat. sub menu berupa jenis surat yang terdiri dari Fasilitas lainnya antara lain pencarian data 11 jenis surat. Isian surat sesuai dengan penduduk dan pengurutan. Pendataan karakteristik jenis surat. Form ini penduduk ini didasarkan untuk isian surat- diperuntukkan sebagai arsip surat keluar.

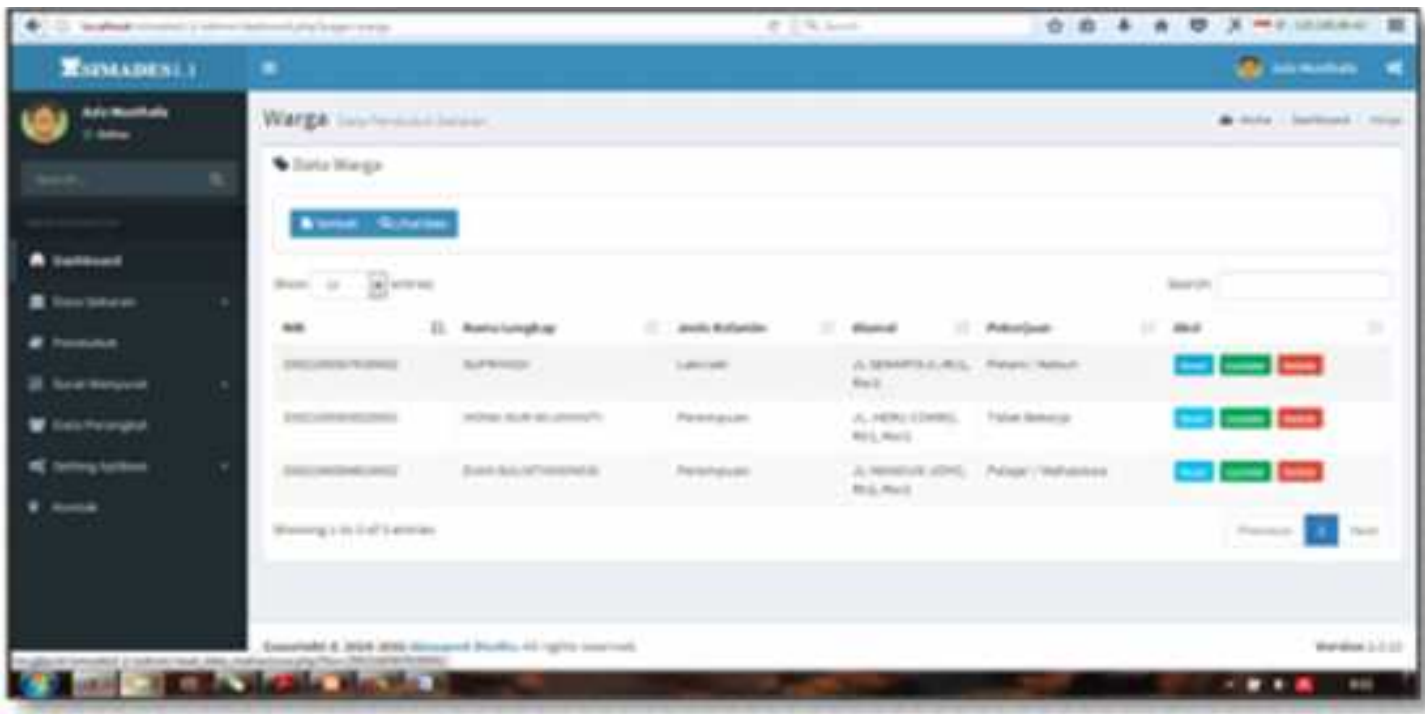

Gambar 6. Halaman Pendataan Penduduk dengan SIMADES

Pada form perangkat antarmuka dan fitur sama dengan form penduduk. Sedangkan form setting dan kontak hanya sebagai form tambahan untuk setting surat dan informasi. Hal terpenting dalam sistem informasi yaitu laporan yang disini dapat berupa cetak dan file PDF.
Pada pengabdian bulan keempat aplikasi ini siap uji coba sesuai dengan skenario percobaan selama 1 minggu. Tahap selanjutnya aplikasi yang telah dibuat diimplementasi di Desa Sekaran dengan bantuan seluruh jajaran perangkat desa dan atas izin dari kepala desa. 


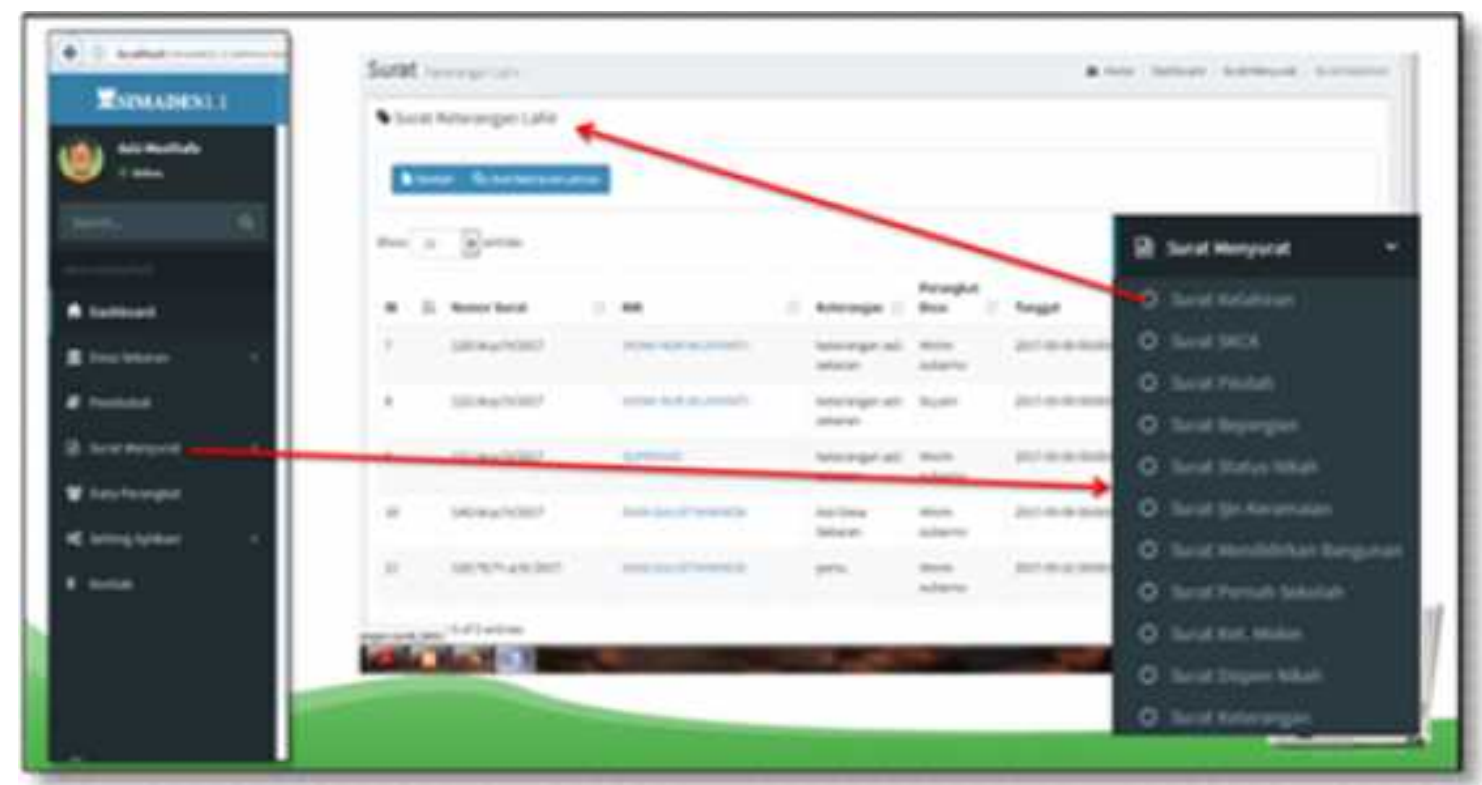

Gambar 7. Halaman Surat menyurat dengan SIMADES

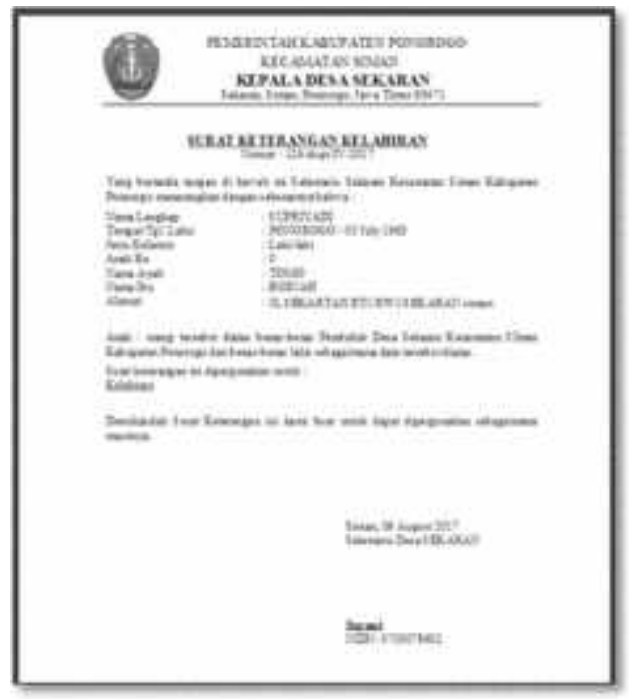

Gambar 8. Contoh laporan surat SIMADES

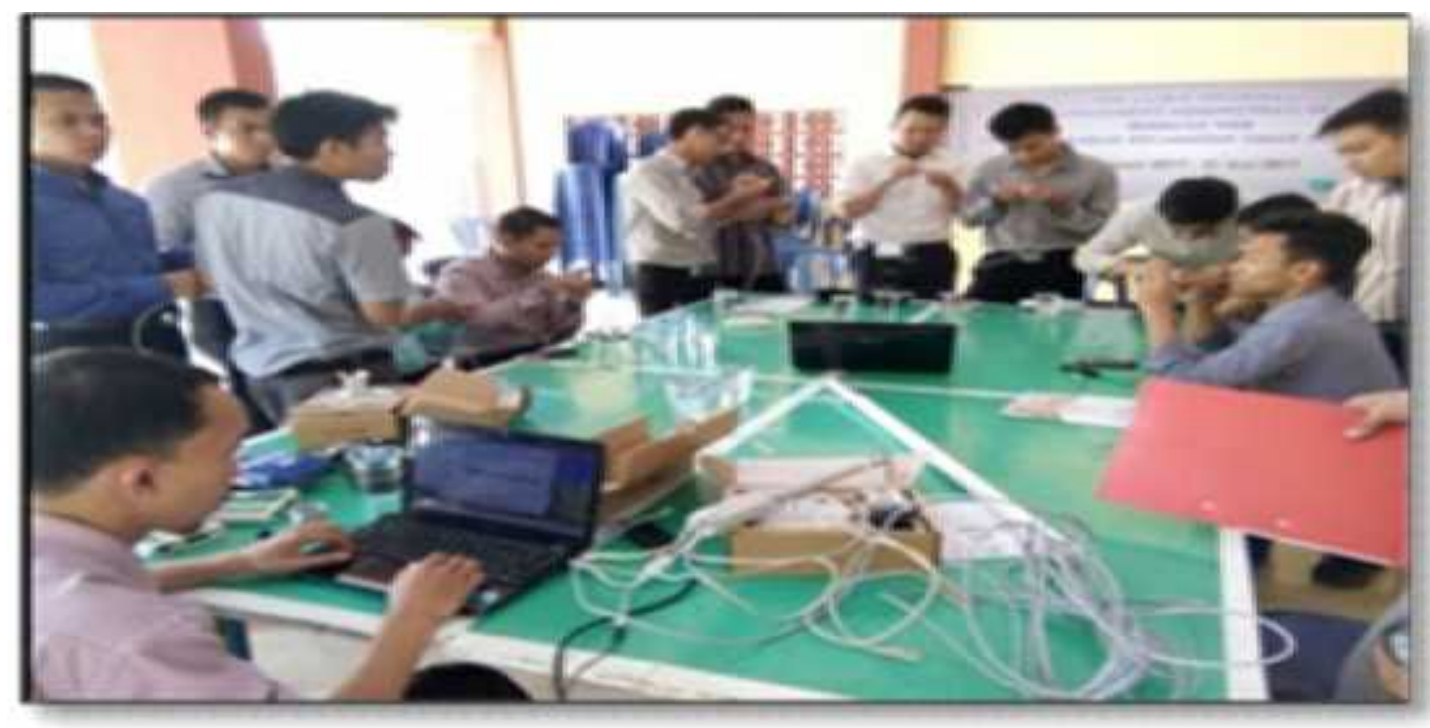

Gambar 9. Dokumentasi pelatihan infrastruktur penunjang SIMADES 


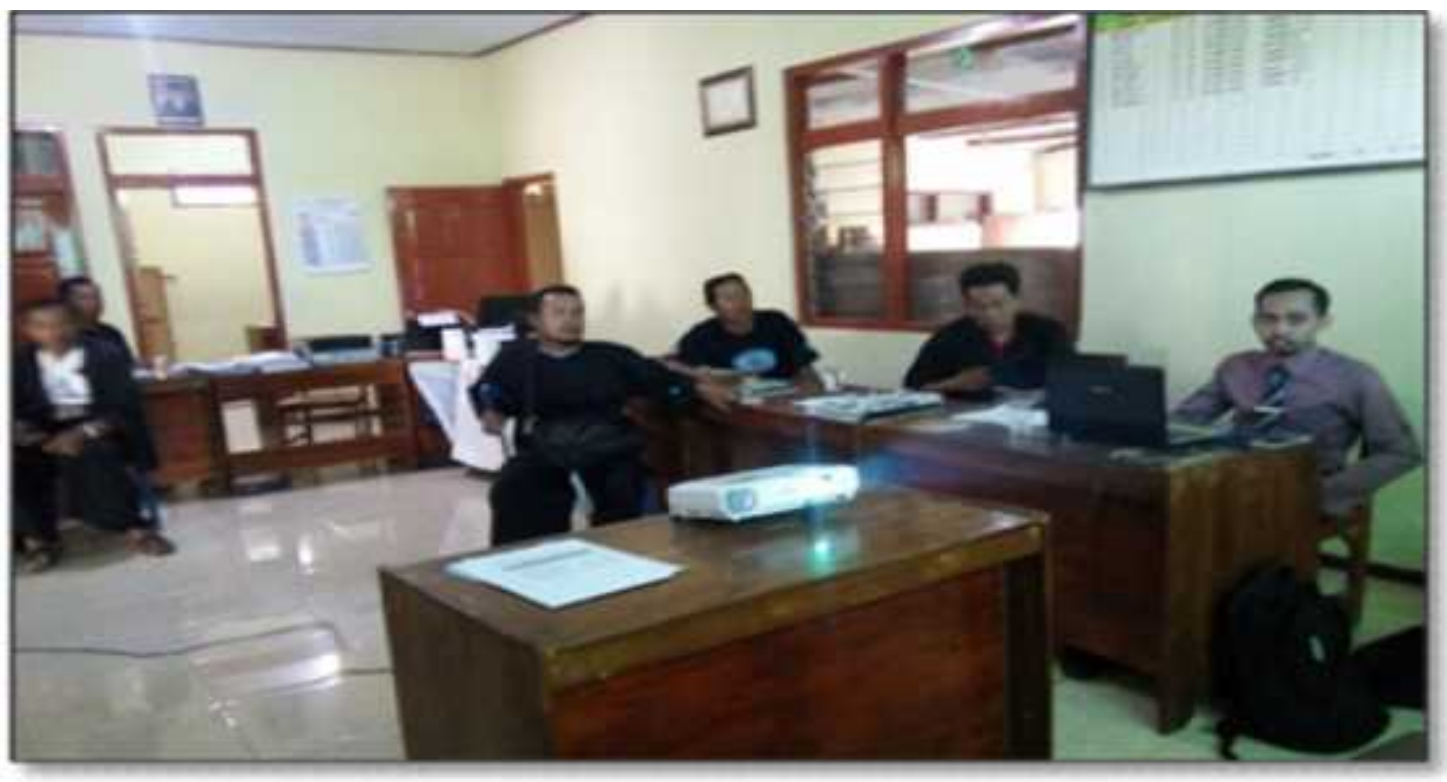

Gambar 10. Dokumentasi pelatihan aplikasi SIMADES

\section{Tahap 2 : Pelatihan}

Diberikan pelatihan tambahan mengenai pemanfaatan, perawatan infrastruktur perangkat jaringan yang didampingi mahasiswa

Kemudian pelatihan penggunaan aplikasi SIMADES untuk menunjang pelayanan administrasi desa. Dari perangkat desa bagian administrasi dan perlengkapan yang mengikuti pelatihan pemanfaatan infrastruktur dan sistem informasi mempunyai prosentase kehadiran $100 \%$.

\section{1) Indikator Keberhasilan}

Hasil yang diperoleh setelah pengabdian ini terdapat peningkatan teknologi dalam hal pelayanan administrasi yaitu terkomputerisasi dan penggunaan aplikasi SIMADES. Dari sisi perangkat desa terdapat penambahan ilmu mengenai wawasan sistem informasi administrasi desa dan aplikasi SIMADES.

Sebagai pengguna aplikasi, perangkat desa memberikan dukungan cukup baik terhadap pelaksaan pembuatan SIMADES yaitu terlihat dari hasil sebaran angket awal antara $80 \%$ memilih sangat setuju dan $20 \%$ memilih setuju. Kemudian sebaran angket akhir dari 7 responden yaitu perangkat desa serta terdapat 10 pertanyaan terkait kepuasan penggunaan SIMADES.

Pertanyaan tentang adanya peningkatan kecepatan proses pelayanan sebanyak 5 reponden memilih sangat setuju dan 2 responden memilih setuju. Pertanyaan tentang desain yang menarik dan kemudahan pemahaman cara menggunakan aplikasi SIMADES, terdapat 6 responden memilih sangat setuju dan 1 responden memilih setuju. Pertanyaan tentang kemudahan pengelolaan data penduduk dan surat-menyurat dengan SIMADES, terdapat 6 responden memilih sangat setuju dan 1 reponden memilih setuju.

Dari hasil tersebut dapat disimpulkan bahwa SIMADES diperlukan bagi mitra khususnya bagian pelayanan administrasi dibagian surat menyurat dan kependudukan.

\section{2) Kontribusi Mitra}

Kontribusi Desa Sekaran pada kegiatan ini menyediakan data terkait kependudukan dan surat menyurat, tempat pengaplikasian sistem baru berbasis sistem informasi, pendanaan untuk infrastruktur, serta teknis saat pelatihan oleh pihak desa, seperti tempat, waktu dan konsumsi.

\section{3) Keberlanjutan}

Permintaan akan keberlanjutan pengabdian kepada masyarakat masih diharapkan dari kepala desa dan perangkat. Permintaan mitra dari segi perbaikan dan penambahan fasilitas dari aplikasi yang tidak hanya kependudukan dan surat menyurat namun juga untuk 
pembuatan Kartu Keluarga. Bagi pengabdi hal ini membuat kemudahan dalam hal transfer ilmu dan teknologi.

\section{SIMPULAN}

Dari Uraian di atas maka dapat disimpulkan sebagai berikut :

1. Pelaksanaan Pengabdian Pada Masyarakat pada Desa Sekaran Kecamatan Siman Kabupaten Ponorogo berlangsung dengan baik sesuai dengan rencana pengabdi.

2. Pencapai tujuan dan luaran dinyatakan berhasil dan di perkuat dengan hasil sebaran angket.

3. Pelatihan berjalan dengan baik membuat perangkat mengerti penggunaan aplikasi
SIMADES untuk pelayanan administrasi desa.

DAFTAR PUSTAKA

Sommerville, Ian. 2011. Software Engineering (Rekayasa Perangkat Lunak). Jakarta: Erlangga.

Azhar, Susanto. 2004. Pengertian Sistem Informasi : Lingga Jaya, Bandung.

Purbo, Onno. 2006. Internet Wireless dan Hotspot. Jakarta. PT. Elex Media Komputindo.

Pressman, R.S. (2010). Software Engineering, A Practitioner'a Approach. Seventh Edition. Singapore: McGraw-Hill Education. 